\title{
INTEGRATION OF VISUAL STIMULI BY THE CRAYFISH CENTRAL NERVOUS SYSTEM*
}

\author{
BY C. A. G. WIERSMA AND T. YAMAGUCHI $\dagger$ \\ Biology Division, California Institute of Technology, Pasadena, California
}

(Received I9 Fune 1967)

\section{INTRODUCTION}

It has been found that integration of visual stimuli in optic nerve fibres can take place in ways which, although unexpected, reflect the types of information used by the animal to react to those environmental changes which are of specific importance for it. The findings in the frog by Barlow (1953) and by Lettvin, Maturana, McCulloch \& Pitts (1959) were the first which made this principle clear. Previous work of a similar nature in the cat, though showing two types of visual processing, was less in contrast with the view that most integration takes place only at higher levels (e.g. Kuffler, 1953). It may be that in the higher mammals, but not in, for example, the rabbit (Barlow \& Levick, 1965), more complex integration is limited to the brain.

A study performed in 1954 (Waterman \& Wiersma, 1963) of unit responses in the optic nerve of crustaceans showed the presence of very complexly integrating elements. This was later confirmed by experiments in the Hawaiian swimming crab, Podophthalmus (Bush, Wiersma \& Waterman, I964; Waterman, Wiersma \& Bush, I964; Wiersma, Bush \& Waterman, 1964). Since the optic nerve in all crustaceans so far studied is a connexion between the brain (supraesophageal ganglion) and four ganglion layers near the retina in the eyestalk, highly complicated reactions can be expected, especially in view of the relatively small number of neuronal elements of the arthropod nervous system (Wiersma, 1957).

Recent work using needle electrodes to record from the optic nerve of the crayfish has again revealed many fibre classes, only some of which respond to visual stimuli (Wiersma \& Yamaguchi, 1966). Among the types found were primary sensory fibres, visual interneurones originating in either eye, mechanoreceptor interneurones with inputs from diverse and often extensive body regions, and highly complexly integrating units. In that paper the differences between the members of any one class and the total number found were presented, together with a preliminary description of their general properties. The purpose of this paper is to give a more extensive description of the properties of several of the visually responsive fibre types, including two optomotor fibres. The descriptions are based on responses obtained from those cases in which the evoked spikes were particularly prominent for a fibre of the class studied.

- This work has been supported by Grant NB-03627 from the National Institutes of Health, Public Health Service.

† Present addreas: Zoological Institute, Hokkaido University, Sapporo, Japan. 
In all experiments middle-sized ( $3 \frac{1}{2}-4$ in) crayfish, Procambarus clarki (Girard), were used. In total more than 600 specimens were investigated, but for the results to be described we limited, as stated, the experiments to units which gave the best signals, which may be several millivolts in size.

The animals were prepared for the experiment by clipping off the rostrum to expose the basal segments of the eyestalks. This operation was performed one or more days before the animal was used to prevent unnecessary blood loss at the time of the experiment. Leads from the optic nerve were obtained in two ways. The active electrode, which consisted of a thin insect needle $(\infty)$ coated with polystyrene except for its finest hand-ground tip, was manually introduced either through the soft membrane between the outer and basal eyestalk segments in a downward direction, or through the soft membrane below the band connecting the two eyestalks in a lateral direction. The exposed needle tip was usually about $2 \mu$ in diameter. With both approaches leads from motor fibres, either in the optomotor nerve and its branches or in the optic peduncle itself, may also be obtained.

During the experiment the animal was clamped over the posterior carapace. This allowed free movement for all appendages, but the claws were usually prevented from moving too much by rubber bands; this was necessary to prevent them from dislodging the active electrode. The indifferent electrode, a coarse needle, was stuck through the anterior carapace between stomach and heart, not piercing either. Deterioration, if it occurred, was almost always due to extensive damage of the ophthalmic artery which sometimes led to anoxia of the optic ganglia, resulting in spontaneous firing of numerous fibres and unresponsiveness to visual stimuli of the eye involved. But in the majority of cases the preparations did not show any untoward effect of the experiment and many specimens survived for months afterwards, or were used for other types of experiments.

The stimulation techniques used varied with the type of fibre under investigation and will be described in more detail for each experiment. In a number of instances we excluded the influence of eye movements by glueing the outer segment of the eyestalk to the carapace with Kodak 910 cement. Remarkably enough, once a successful lead of a unit is obtained, the needle will commonly stay in place for the duration of the experiment unless inadvertently dislodged by a mechanical pull. This is as true for eyes that are free to move as for the glued-down ones. Our most successful needles were ground to have a quickly tapering end on a cylindrically shaped part of about $0.3 \mathrm{~mm}$. length, after which the original needle taper was resumed. This shape was presumably so favourable because it prevented the connective tissue sheaths around the optic nerve from pulling the tip out by their elasticity.

The action potential spikes of the unit, together with various parameters of the stimuli used, were recorded after preamplification ('Tektronix 122) on a seven-channel magnetic tape recorder (Consolidated Electrodynamics Corp.) at a speed of ${ }_{5} \mathrm{in}$./sec. The recorded spikes were for all purpose in this paper identical with the original ones, which were always monitored with an oscilloscope and a loudspeaker. All figures of impulse discharges were obtained from playback of the tapes. 


\section{RESULTS}

\section{Sustaining fibres}

In the crayfish each eye appears to send to the brain and to the optic ganglia of the other eye direct information concerning the brightness of areas of the retina via fourteen fibres (Wiersma \& Yamaguchi, 1966). Though minor differences between these fourteen units may exist, the major properties of their responses are quite similar. The members of this and all other classes reacting mainly to visual input have been differentiated on the basis of the specific area of the eye to which they respond. The receptive fields and code numbers of the fibres quoted in the text are shown in Fig. I.

A
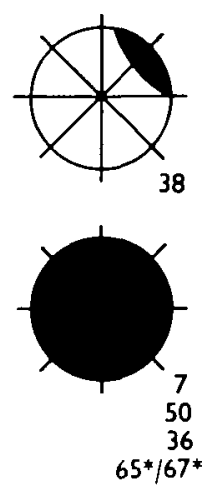

D
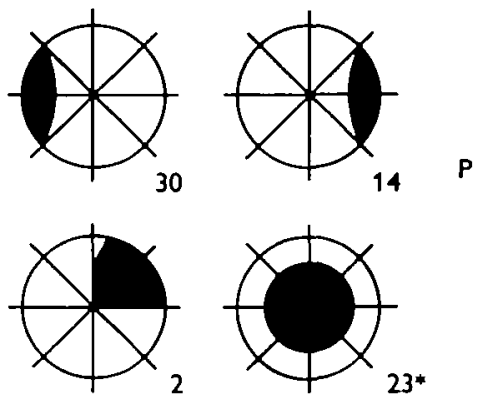

2

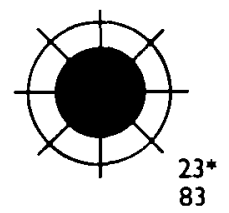

Fig. I. Excitatory sensory fields (in black) of the visual interneurones, with their code numbers on the lower right, quoted in the text. - For the space-constant fibres, this is the largest field possible.

Table I. Latencies of homolateral sustaining fibres

\begin{tabular}{|c|c|c|c|}
\hline \multirow[b]{2}{*}{ Code no. } & \multicolumn{3}{|c|}{ Latency (msec.) } \\
\hline & $\mathrm{LI} * \mathrm{I}$ & $\mathbf{L I}=0.3$ & $L I=0.1$ \\
\hline $\mathrm{O}_{\mathbf{I}}$ & $24-37(4) \dagger$ & $45-46(2)$ & $8 I(I)$ \\
\hline $\mathrm{O}_{2}$ & $24-40(4)$ & $32-50(3)$ & $40-52(2)$ \\
\hline $\mathrm{Og}_{9}$ & $28-42(4)$ & $33-63(4)$ & $45-59(3)$ \\
\hline $\mathrm{O}_{14}$ & $24-37(5)$ & $28-39(4)$ & $50-96(4)$ \\
\hline$O_{16}$ & $28(1)$ & 4I (I) & - \\
\hline$O_{19}$ & $24-4 \mathrm{I}(4)$ & $28-56(3)$ & $65-102(2)$ \\
\hline $\mathrm{O}_{20}$ & $24-28(2)$ & $37(\mathrm{I})$ & - \\
\hline $\mathrm{O}_{2 \mathrm{I}}$ & $24(1)$ & $40(1)$ & - \\
\hline $\mathrm{O}_{22}$ & $22-37(2)$ & $26-41(2)$ & $37-59(2)$ \\
\hline $\mathrm{O}_{23}$ & $28-43(3)$ & $40-52(3)$ & $78(\mathrm{I})$ \\
\hline $\mathrm{O}_{30}$ & $33-39(3)$ & $40-52(3)$ & - \\
\hline $\mathrm{O}_{3} 8$ & $21-37(5)$ & $24-3$ I $(5)$ & $37-42(4)$ \\
\hline $0_{56}$ & $24(1)$ & 3I (I) & - \\
\hline$O_{72}$ & - & - & - \\
\hline$O_{73}$ & $22-37(3)$ & $35-52(3)$ & $52-8$ I (3) \\
\hline $0_{74}$ & $24-46(4)$ & $37-56(3)$ & $96(1)$ \\
\hline
\end{tabular}


Each unit integrates the light intensities in its own excitatory visual field and is under the inhibitory influence of the whole remainder of the eye surface. They respond to increasing light intensities with a decrease in latency down to a minimum of about $20 \mathrm{msec}$. (see Table I), and an increased frequency both in the initial burst and during the gradually established sustained firing rate. In contrast to similar fibres in other decapods the crayfish fibres are normally silent when no light is present on the retina, though under unfavourable conditions discharges do occur in the dark. The fibre of this class most used in the following experiments was $\mathrm{O}_{3} 8$, the upper back rim fibre.

The effect of small light spots. The following properties were found with the aid of small light pipes which were brought close and perpendicular to the eye surface by micromanipulation. The light intensity could be varied, but was maximal at about 12 foot-candles. Using a single light pipe, the reaction to turning light on was substantially the same over most of the total excitatory area, and consisted of an initial burst followed, sometimes with a noticeable silent period, by a very gradually adapting sustained response, and immediate cessation on 'off'. However, changes in the discharge were observed near the boundary, as shown in Fig. 2. When the light spot fell still mainly on the excitatory field, as in B, the discharge shortened, without an appreciable lengthening of the latency. When the spot was somewhat farther out, both an 'on' and an 'off' response occurred (C). Just slightly more peripherally, we sometimes succeeded in obtaining only an 'off' response (D) which was always short in duration with maximally three spikes. No responses were ever triggered farther away from the excitatory field (E), but such stimuli do inhibit excitatory discharges.

This inhibition is illustrated in Fig. 3, in which again the only light stimuli were provided by light pipes. In Fig. ${ }_{3} \mathrm{~B}$ the second light was located at the opposite pole of the eye from the excitatory light on the fibre's field. Turning it on during the discharge caused by light I showed a very pronounced inhibitory effect, but on turning it off the original frequency was quickly restored. Increasing the intensity of the light on an inhibitory area resulted in an increased inhibitory effect as shown in Fig. 4. Fig. $3 \mathrm{~A}$ shows the effect of summation when both light sources were in the excitatory field. Here the effect of turning the second light on was additive as one would expect, but on turning it off there occurred a period without spikes and with a gradual return to the maintained frequency caused by light $\mathrm{I}$. The same effect was also seen when light $I$, instead of 2 , was turned off first. This finding is representative of all such experiments and indicates that the inhibitory influence of other areas also exists within the excitatory field itself (see Discussion).

The effect of light interruptions. Because other fibre types, as will be shown, are especially sensitive to movements, the sustaining fibres were also investigated with moving lights and shadows. Under most circumstances the results are completely explicable on the basis of light intensities and adaptation rates. Thus a small light moved over the excitatory field caused less adaptation in the discharge rate than when stationary. When a light beam on the excitatory area was turned off for short times, a burst followed re-illumination. For short interruptions, but not for longer ones, the number of spikes in the resulting burst was proportional to the duration of the interruption. For short interruption times, the total number of impulses stayed thus about the same as that elicited by continuous illumination during the experimental period. This is illustrated in Fig. 5, in which there are about the same number of spikes 

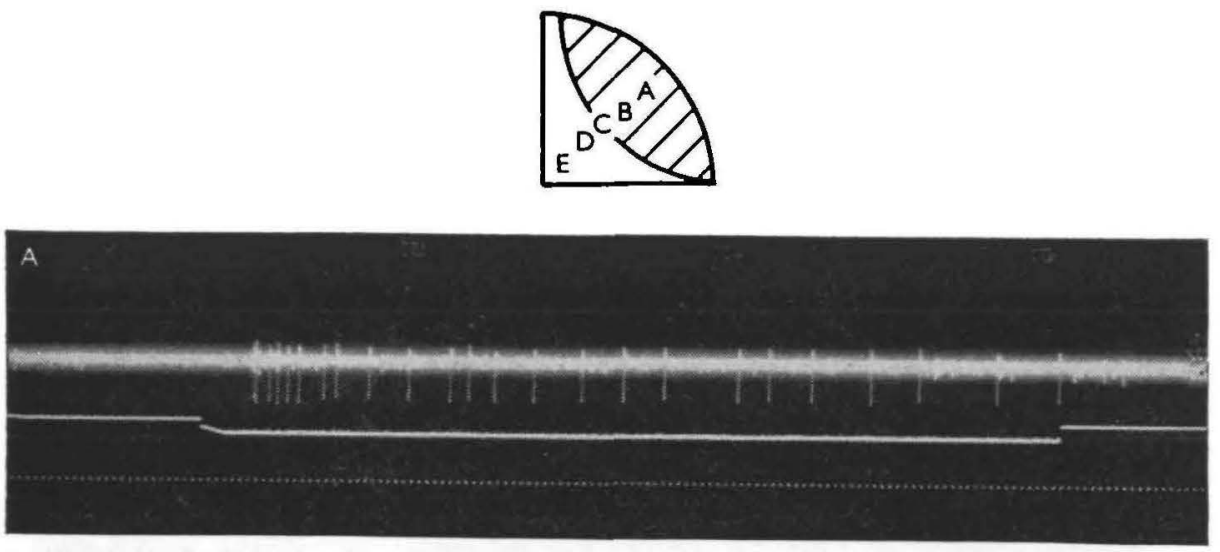

$$
\text { B }
$$

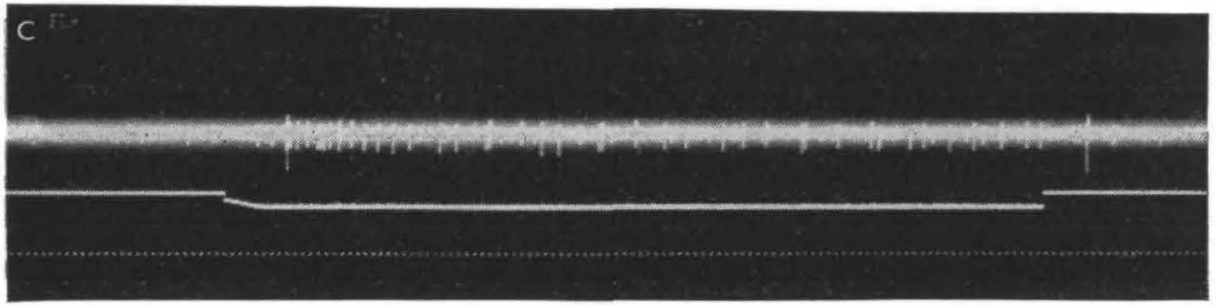

D

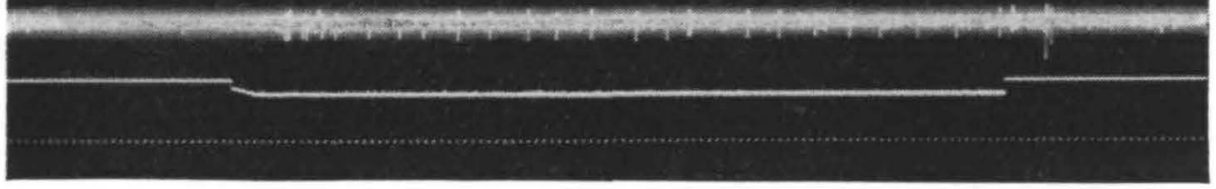

E

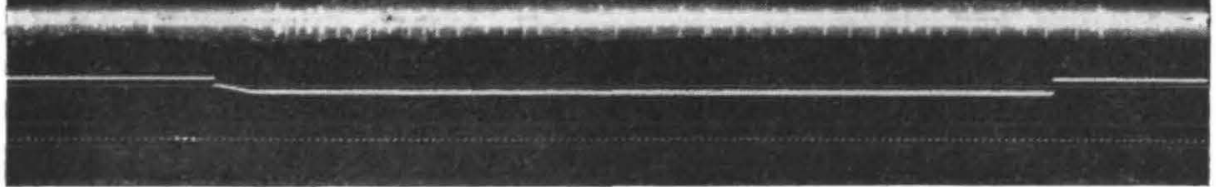

Fig. 2. Effect of small light spots on different parts of the retina on the discharge of $\mathrm{O}_{3} 8$, the sustaining fibre for the upper back eye rim. In the inset the approximate locations of the spot for the records A-E are indicated, but the distances between B, C and D were, in reality, closer. A. Discharge as present for all locations away from the border of the field. B. Light spot mainly within border. C. Light spot on both sides of border. D. Light spot mainly outside border. E. Light spot totally outside. The small spikes are due to another sustaining fibre, with a more central and larger field. Time: $\frac{1}{\delta}$ sec. Lower signal down, light on. 
(38) in all three records, or a mean of $7 / \mathrm{sec}$., which was approximately the basic discharge rate at this level of adaptation.

However, when the light interruption was due to a shadow moving over the excitatory field, instead of being caused by turning the light off, this relation no longer held. For this purpose a Hewlett-Packard low-frequency generator was used to drive a loudspeaker cone in a triangular mode, resulting in linear, but reversing, horizontal motions of an object whose vertical shadow was projected on the eye.
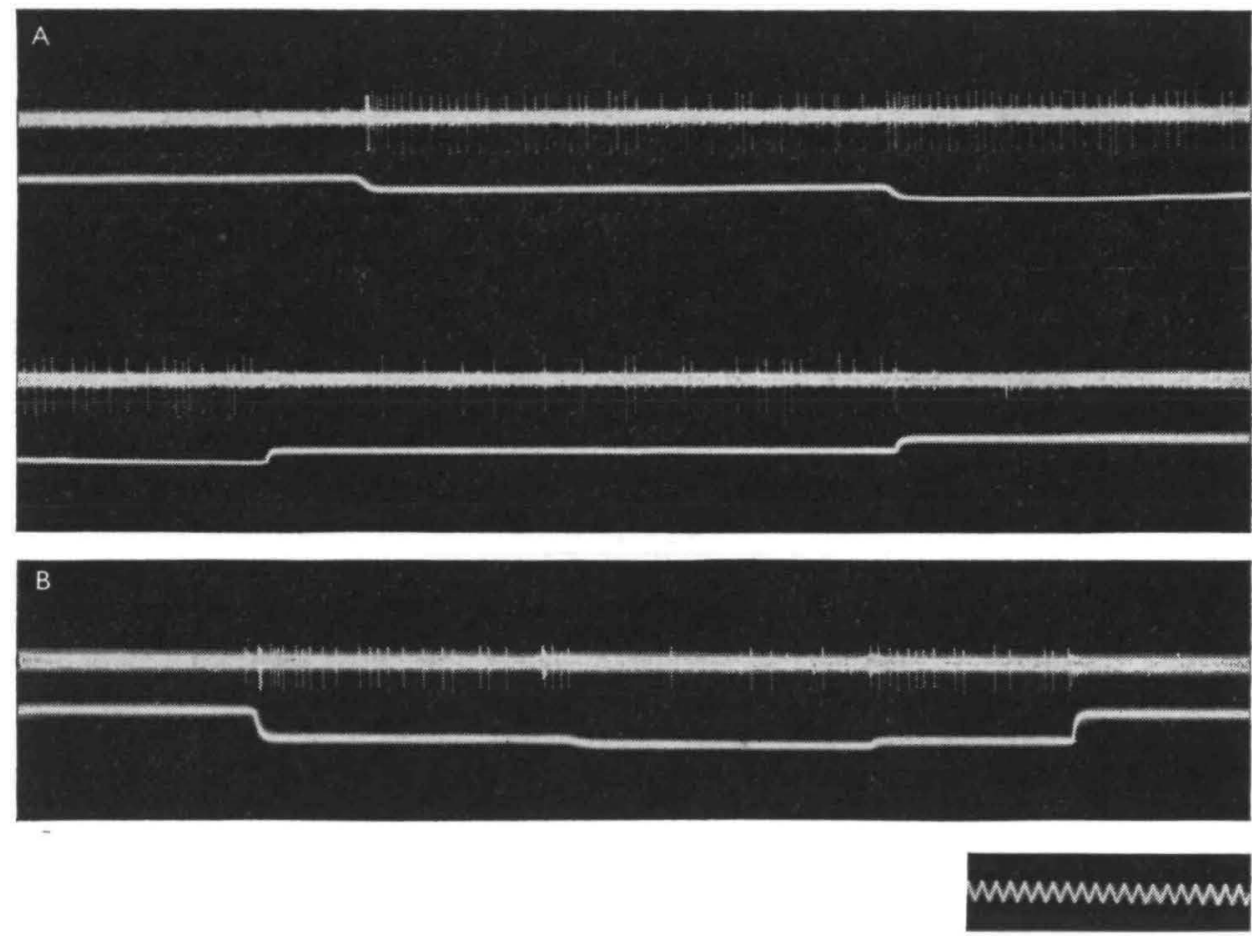

Fig. 3. Effect of two small light spots on discharge of sustaining fibre $\mathrm{O}_{3} 8$. A. Both spots inside excitatory field, effect of turning on two lights in succession and then turning of first one and then the other. Note silent period after first 'off'. B. Effect of second light on opposite pole of the eye (lower front rim) during illumination of excitatory area, resulting in inhibition of discharge. Time: 1o cyc./sec.

Illumination was provided either by a single light beam, in which case the shadow of the object, some $8 \mathrm{~cm}$. in front of the eye, had sharp edges, or by the room lights, when the shadow on the eye was vague. When the movement was fast more impulses per second were present than when it was slow. Figures $6 \mathrm{~A}$ and $6 \mathrm{~B}$ show the difference between a shadow passing through a light beam at $\mathrm{I} / \mathrm{sec}$. and at $9 / \mathrm{sec}$; the latter gave about $33 \%$ more impulses. In Figs. $6 \mathrm{C}$ and $6 \mathrm{D}$ the diffuse room light was used for illumination and the same target was moved. Under these conditions the frequencies obtained were lower, but the same proportional increase was present. In other experiments we have further investigated this effect. By selecting the optimal width of the target one can elicit as many as three times more impulses per second than are present in the sustained discharge. Thin targets will synchronize a single spike 
discharge with each pass, even when the illumination is diffuse. The fibre can 'see' a thin insect needle $(\infty)$ passing at a rate of $10 / \mathrm{sec}$. $80 \mathrm{me} 5 \mathrm{~cm}$. in front of it, whereas at slower rates (e.g. I/sec.) there is no noticeable effect of so thin an object. At the frequency of $\mathrm{ro} / \mathrm{sec}$. and at the deflexion distance used each ommatidium in the excitatory field was shadowed for some five milliseconds. By broadening the shadow more impulses are obtained in each burst caused by a single passage, up to a maximum of about five. The phenomenon shows practically no adaptation, and the increased frequency thus lasts for an indefinite time. It is without directional sensitivity.
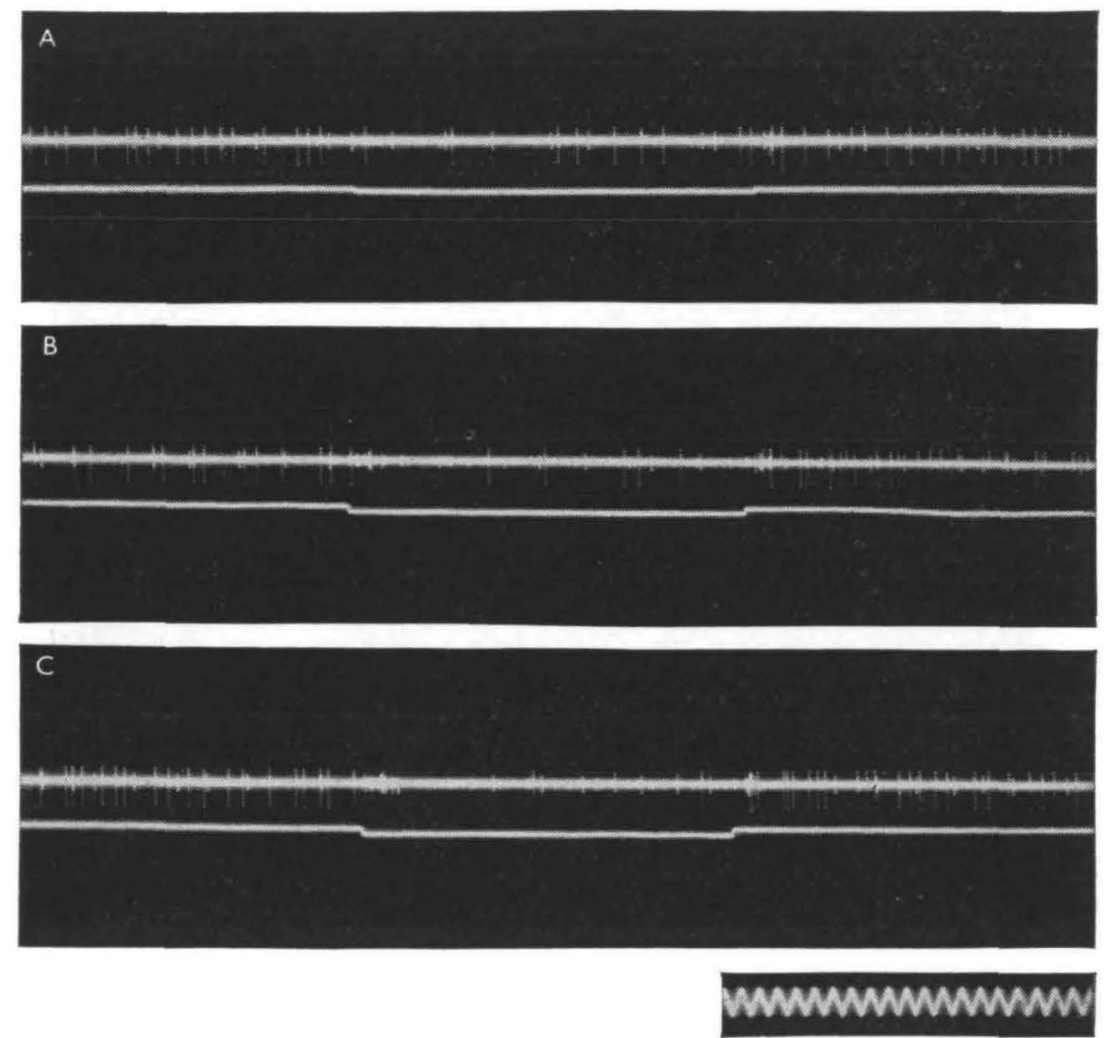

Fig. 4. Effect of increased intensity (indicated by lower trace) of inhibiting light (on opposite pole of the eye) on sustained discharge of $\mathrm{O}_{38}$. Note increase in effect. Time: ro cyc./sec.

The effect of the 'excited state'. Another influence on the firing frequency of the sustaining fibres was discovered by noting that there is a direct correlation between it and the state of excitement of the animal. Changes in the excited state occur spontaneously or can be induced by mechanical stimulation. The excited state expresses itself by increased movements of body parts and also by an increased firing of certain interneurones. The increased discharge of the visual interneurones might be due to small eye movements accompanying the excited state, which would cause a shift in the division of light over the eye surface, leading either to more excitation or less inhibition. However, the phenomenon persisted when the eyes were immobilized by glueing them to the carapace. The enhancing effect of an excited state is not limited to 
the adapted frequency but also involves the primary burst. In Fig. $7 \mathrm{~A}$ a light flash of about $\mathrm{r}$ sec. duration was given when the animal was quiet, in B during an excited state brought about by mechanical stimulation. The total number of impulses elicited was $1_{3}$ and 25 and there were clearly about $50 \%$ more impulses in B in the initial burst (here consisting of two parts in both records). Under no circumstances have we observed a firing of the sustaining fibres caused by mechanical stimulation only. In Fig. 8 we show a case in which a lead happened to register simultaneously the spikes
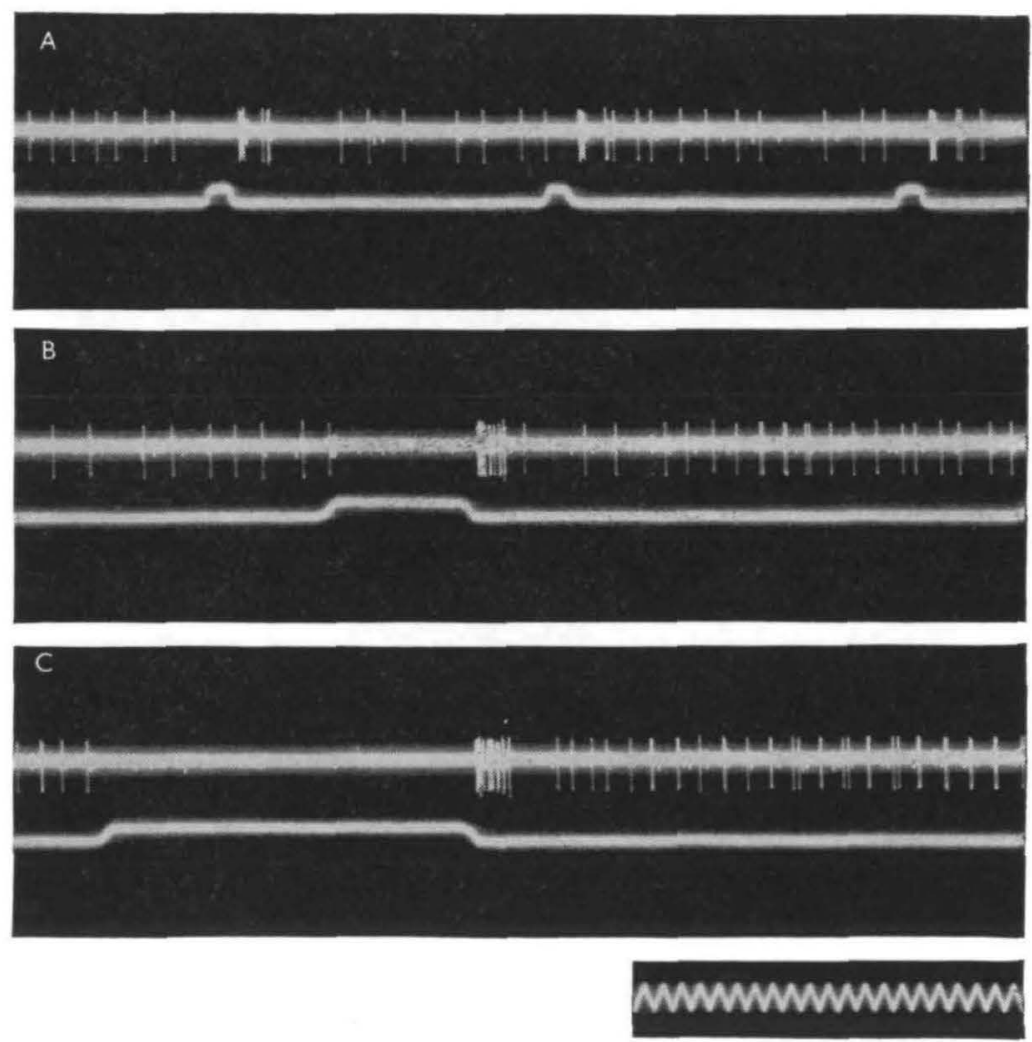

Fig. 5. Effect of short interruption of illumination on excitatory field of $\mathrm{O}_{3} 8$ on the sustained discharge. In $\mathrm{A}$, three interruptions of $0.1 \mathrm{sec}$; in $\mathrm{B}$, one of $0.75 \mathrm{sec}$.; in $\mathrm{C}$, of $2.0 \mathrm{sec}$. The total number of impulses in each record remains practically constant $\left({ }_{3} 8\right)$, the interruptions being compensated by the bursts. Time: $10 \mathrm{cyc} / \mathrm{sec}$.

from $\mathrm{O}_{3} 8$ and from a bilateral 'activity' fibre (possibly $\mathrm{O}_{71}$ ) for the whole body, but which itself was not reactive to light. It can be seen that as the excited state increases or decreases both fibres change their discharge rates, though not to the same degree. Many more data of this type would be required to establish the proportionality of this relationship under different light intensities.

Dark discharges. It has been mentioned above that in deteriorated preparations the sustaining fibres show spontaneous dark discharges. In Fig. 9 a fibre with a fairly strong dark discharge is seen to react to light in its excitatory field with an increased frequency, and the dark response is inhibited for a considerable time after the light-evoked one 


\section{Visual integration in crayfish}

(Fig. 9A, B). The dark discharge is inhibited by light on the retina outside of the excitatory field as shown in Fig. 9 C.

During the development of such deterioration the preparation will show a succession of response types. For instance, when the firing frequency in the dark is still low the
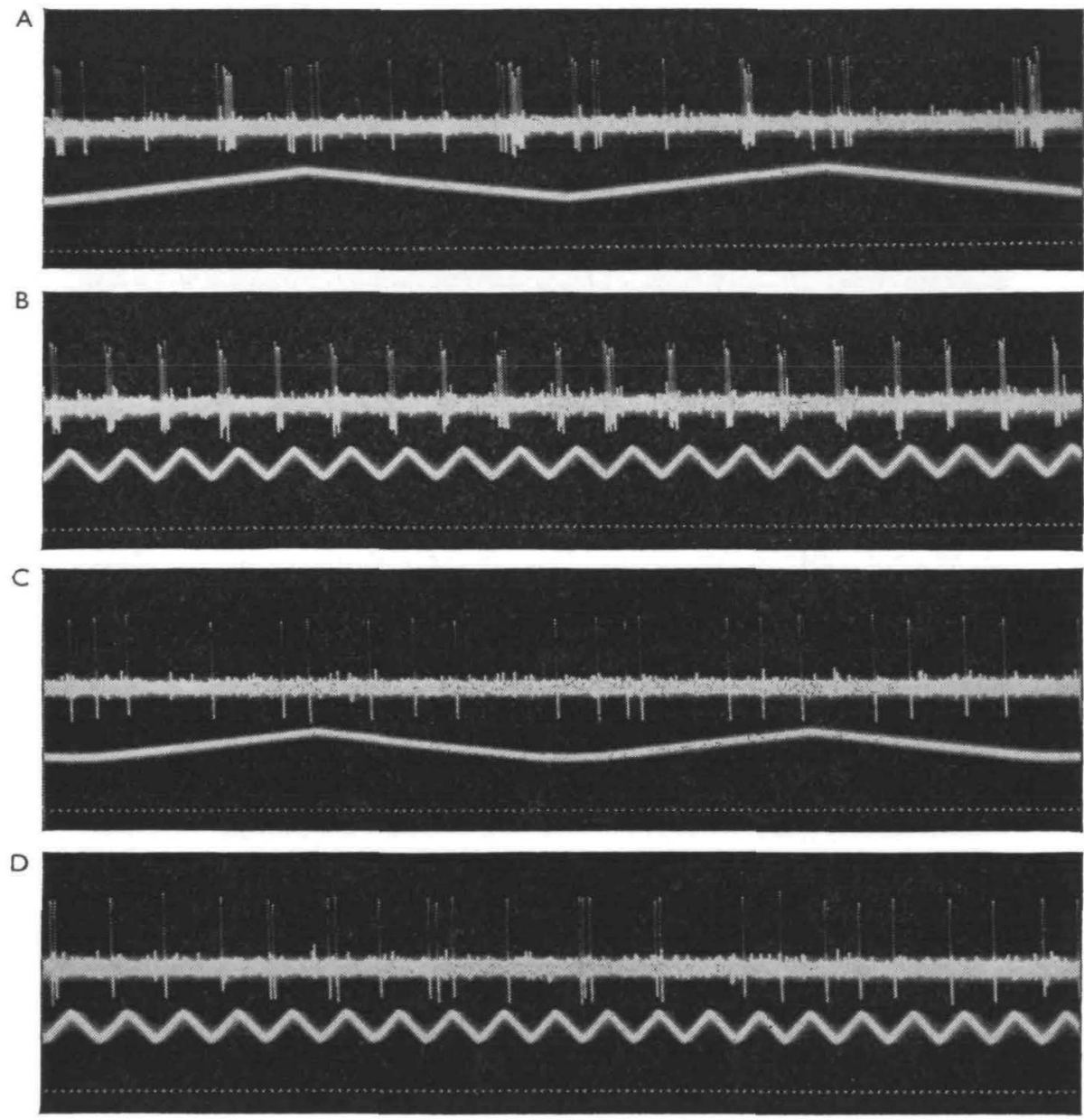

Fig. 6. Effect of passing a shadow (of a $4 \mathrm{~mm}$. wide target) over the excitatory field of $\mathrm{O}_{3} 8$ at different frequencies, and thus at different velocities. In $A$ and $B$, the field was lighted by a single light source; in $C$ and $D$, under general illumination. $A$ and $C$, target passes to and fro $\mathrm{I} / \mathrm{sec}$; in $\mathrm{B}$ and $\mathrm{D}$, at $9 / \mathrm{sec}$. Note synchronization and bursting at $9 / \mathrm{sec}$. Time: $\frac{1}{6} \mathrm{sec}$. Distance between target and eye, $8 \mathrm{~cm}$.

effect of bringing about an excited state will still increase the firing frequency during a sustained reaction to light. When the dark-discharge rate increases, this effect is no longer observable. About this time the response to light in the excitatory field also starts to disappear, whereas the inhibitory effect of light on the surround will be still quite noticeable, though eventually it also vanishes. 


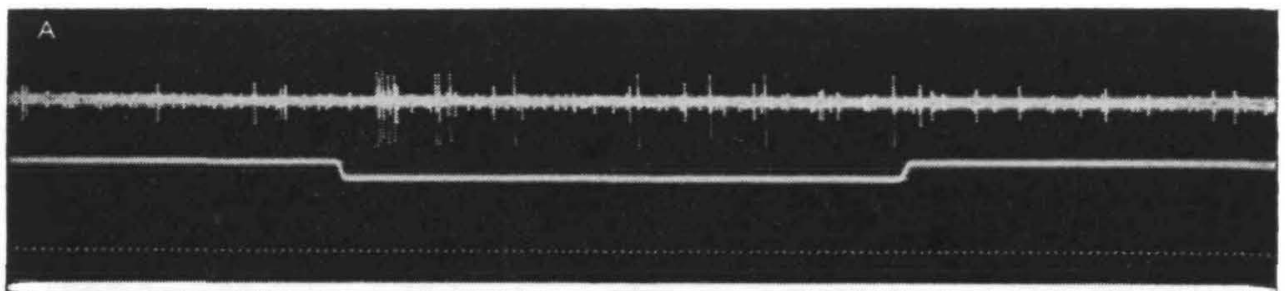

B

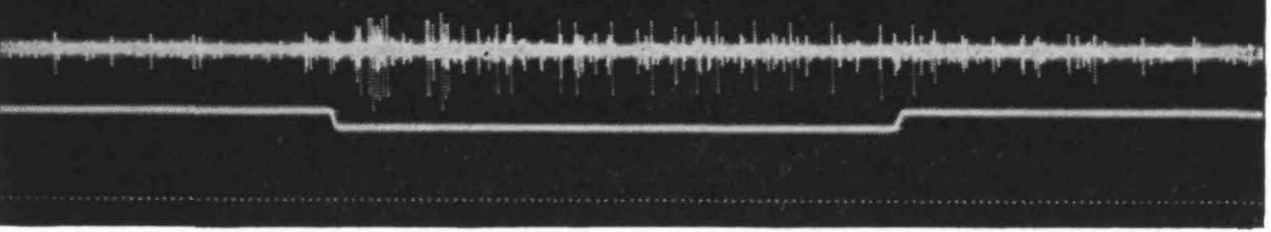

Fig. 7. Influence of excited state on impulse triggering by a light flash (lower beam) of $\mathrm{I}$ sec. duration. In the quiet animal, A, 13 impulses were triggered. In the excited state, B, about 25 impulses of $\mathrm{O}_{3} 8$ appear. Note the increased frequency of another non-light-sensitive fibre in B. Time: $\frac{1}{80}$ sec.

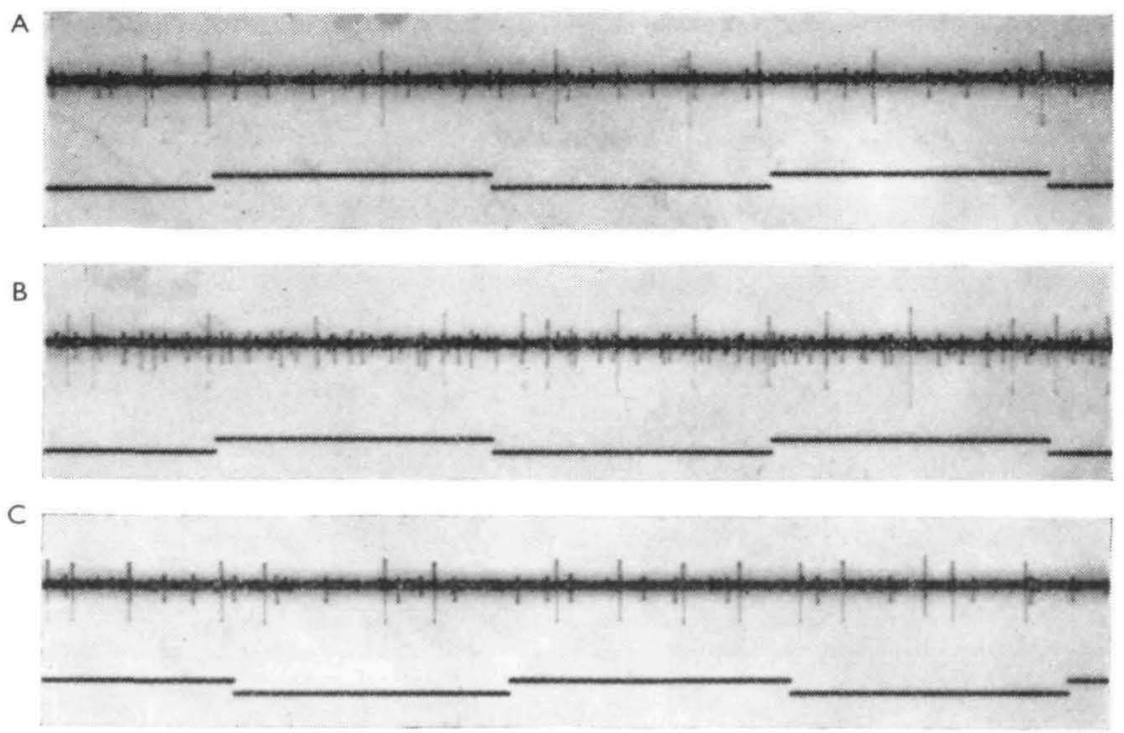

D

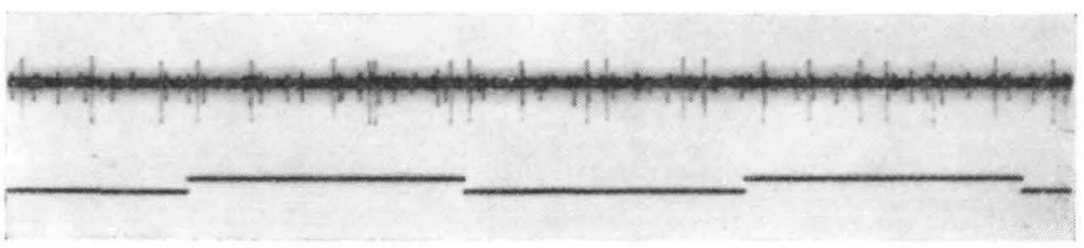

Fig. 8. Influence of excited state on a sustaining fibre and an activity fibre. Simultaneous record of $\mathrm{O}_{3} 8$ 's adapted discharge (larger spikes) to a low (A and $\mathrm{B}$ ) and a higher (C and D) light intensity, and of the activity fibre (smaller spikes). In $A$ and $C$ the activity fibre fired at a frequency of 12 impulses/sec., whereas $\mathrm{O}_{38}{ }^{\prime} \mathrm{s}$ discharges were respectively 4 and $8 / \mathrm{sec}$. In $\mathrm{B}$ the activity fibre's firing rate is $28 / \mathrm{sec}$., $\mathrm{O}_{3} 8$ 's $7 / \mathrm{sec}$., whereas in $\mathrm{D}$ the activity fibre fired at 22/sec., $\mathrm{O}_{3} 8$ at $\mathrm{I}$. During $A$ and $C$ the animal showed no movements, during $B$ and $D$ marked movements of appendages occurred after mechanical stimulation. 


\section{Dimming fibres}

The study of the reactions of this fibre type has been less satisfactory and is incomplete. Dimming fibres are much smaller than sustaining fibres and when found are usually accompanied by the latter, which makes it difficult to measure their discharge rate during illuminations. In such circumstances one can, however, observe their reactions to light-off or to light-dimming. The reaction patterns of dimming fibres are like those of the sustaining fibres but reversed with respect to changes in illumination. On light decreases they start with a burst, followed by a sustained discharge with a lower frequency. This discharge continues for any length of
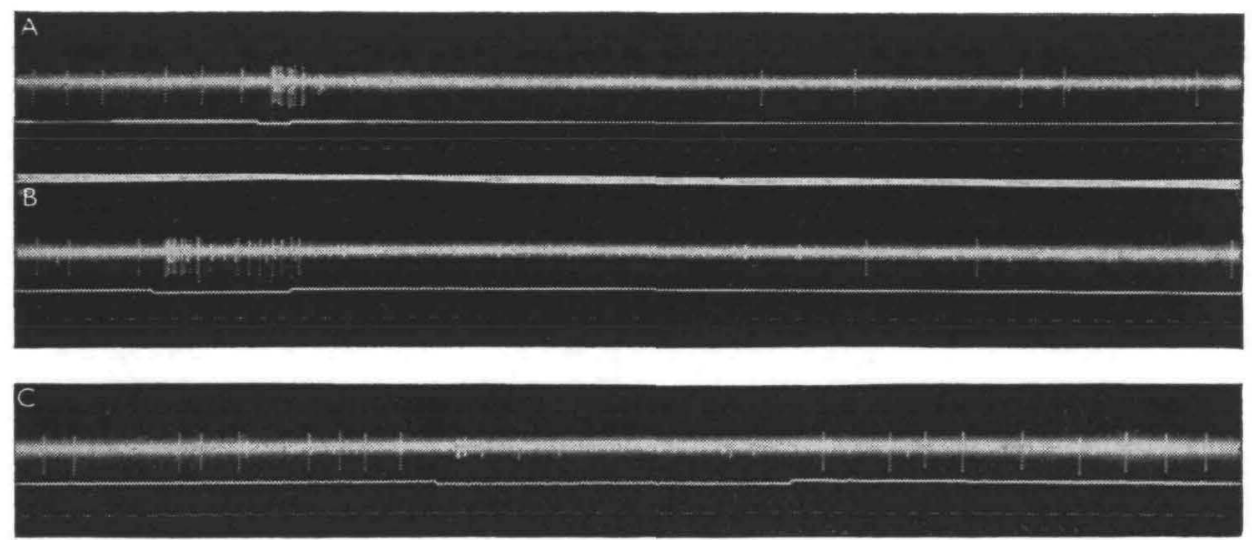

Fig. 9. Dark discharge of a sustaining fibre $\left(\mathrm{O}_{2}\right)$ and the effects of light flashes in the excitatory area $(\mathrm{A}, \mathrm{B})$ and outside it $(\mathrm{C})$. Time: $\frac{1}{\gamma} \mathrm{sec}$.

time, and is inversely proportional to light intensity. Even at relatively high light levels some spikes will eventually appear, but it is unknown whether this is also true for bright light. As in the case of the sustaining fibres each dimming fibre has its specific excitatory field, that area of the eye in which light-dimming causes an increase in discharge rate. In Fig. Io we present results on a dimming fibre which was investigated more extensively. In $\mathrm{A}$ it is obvious that the fibre discharges strongly after lightdimming. In $\mathrm{B}$ and $\mathrm{C}$ it is shown that the fibre reacts more to fast than to slow moving shadows over its excitatory field. The effects of light changes in retinal areas surrounding the excitatory field are as yet unknown. Also uncertain is the influence of the excited state on these fibres.

\section{Centrifugal sustaining and dimming fibres}

Such fibres all appear to be just branches of the ones described above. However, their discharges differ from those of the centripetal parent fibre in two respects. The first is a considerably increased latency, to about $40-50 \mathrm{msec}$. (see Wiersma \& Yamaguchi, r966). This time is longer than might be expected from just an increased conduction distance in a fibre with constant diameter. The second is that the initial burst shows often a pronounced reduction in height for spikes that follow each other at short intervals, and it is likely that some spikes present in the parent fibre are lost 
in this way. Whether or not these two differences are solely due to the markedly smaller diameter, which is also indicated by the mean spike height recorded, or whether other factors, such as a synaptic transmission, are responsible is not certain. We are inclined to favour the first explanation. Regarding the functional significance of these fibres' crossings, it was stated previously (Wiersma, Bush \& Waterman, 1964): 'One likely hypothesis... is that fibers of a given type coming to the optic ganglia will influence particularly those reactions which are related to the specific stimulus parameters they sense.' This hypothesis appeared strengthened by the fact that the twin fibres are close neighbours in the optic nerve (Wiersma \& Yamaguchi, 1966). But we have been unable to find any influence on the discharge of any ipsilateral sustaining fibre when light is presented to the symmetrical (or any other) area of the contralateral eye.

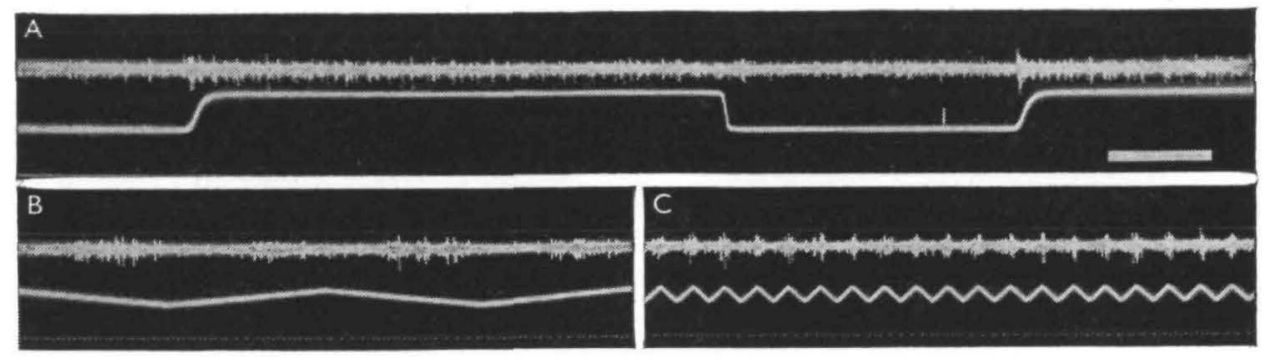

Fig. 1o. Response of a dimming fibre $\left(\mathrm{O}_{5} \mathrm{O}\right)$ to light dimming in $\mathrm{A}$, and to a shadow (4 $\mathrm{mm}$. wide target) moving over the eye at $1 / \mathrm{sec}$. (B) and (C) ro/se c. Time for A, 1 sec. Mark on lower beam during second illumination, first of two impulses in $\mathrm{O}_{50}$ during light period. Time in $\mathrm{B}$ and $\mathrm{C}$, to sec.

\section{Movement fibres}

Like other decapod crustaceans the crayfish has another main class of light-sensitive fibres with properties which differ greatly from the sustaining and dimming fibres. The adequate stimulus for this class is moving objects. The common type in the crayfish has been named the 'jittery' movement fibres and includes again a number of units which, but for their receptive fields, have much the same properties. At present it is known for certain that I I such fibres exist and it is likely that the total, as for the sustaining fibres, is 14 (Wiersma \& Yamaguchi, 1966). Of these the most convenient for experimentation is one of two larger fibres of this group, which has the total retina for its excitatory field. This fibre's code number is $\mathrm{O}_{7}$, and it is nicknamed 'The Happy Dog Fibre' for reasons to be explained below.

The crayfish jittery movement fibres are, like the sustaining fibres, normally silent in the dark, and react very little or not at all to an increase in illumination. To sudden darkening they may respond with a very short 'off' burst, provided that their sensory field was illuminated for some considerable time. When a light is flicked on and off several times per minute, the 'off' discharges shorten and soon disappear altogether. In addition, the size of the burst is not correlated with the light-intensity change.

This last feature appears to be connected with another outstanding property of movement fibres in general, namely the faculty to react to moving objects to the same extent in bright light and in much dimmer light (Barlow \& Hill, 1963). This same property appears also responsible for the fact that the contrast of the moving object with the background is unimportant within a wide range. There are, of course, limits 


\section{Visual integration in crayfish}

in both aspects; when there is too little illumination or not enough contrast the reactions will be weaker or absent, but it is difficult to determine these limits with any precision since they vary with circumstances. For instance, after a period of bright illumination an object may not be immediately seen to move in dim light, but may regain its effectiveness with dark adaptation. In contrast to the three types of movement fibres of Podophthalmus the 'jittery' movement fibres of the crayfish have no pronounced preference for a certain range of speed, but here again there are limits, neither very slow not very fast motions are effective.

The fibres react about as well to moving objects which are lighter than the background as to ones that are darker, provided they are relatively small. Nevertheless, it can be shown that only a decrease in light flux in their collecting stations is excitatory. When a single small lighted surface is gradually darkened by bringing a black disc in front of it a discharge will be elicited, but no reaction is obtained when the lighted area is uncovered. When a single black edge of a large carton is moved into the sensory field a discharge will result, but the introduction of a similar white edge will have no effect. It can be concluded that for objects lighter than the background the response is caused by the trailing edge, whereas it is the leading edge for objects darker than the background.

Moving objects: the predictability of their direction and the habituation to them. In all the above instances where a reaction was obtained to a moving object, this was of short duration only. Thus the edge of a large black carton is 'seen' only at the time and shortly after it enters the periphery of the sensory field, but not afterwards unless a pause in the movement is made. We have used several types of stimuli to elucidate this finding, using a variety of tools.

With one set-up the shadow of a rod projected on a white card in the fibre's field was moved by mounting the rod on a motor-driven drum. The shadow had a width of about half an inch. The shadow caused a distinct discharge when it entered the sensory field but, in general, there were no subsequent discharges, again unless motion was temporarily stopped, after which renewed movement would cause a short burst. However, when there was a stationary shadow in the field, a burst would occur when the travelling shadow had crossed it. This set-up was also used to demonstrate that light intensities and contrast had, within the wide ranges mentioned, little effect on burst size. However, it should be realized that the pronounced 'habituating' properties of the 'jittery' movement fibres make it very difficult to obtain identical results under any circumstances. The repetition of an identical stimulus results for a considerable time in little or no discharge, whereas any movement in a part of the fibre's field which has not been exposed will cause an outburst.

Another instrument with which the properties of the 'jittery' movement fibres have been investigated consisted of a dome, lighted from its rim, and painted light grey inside. A target, usually a black round disc, was moved over the inner surface by a magnet on the outside. The dome had a radius of $5 \mathrm{~cm}$., the disc's diameter being generally $\mathrm{I} \mathrm{cm}$. The crayfish eye was centred, however, at some distance $(\mathrm{I}-2 \mathrm{~cm}$.) away from the dome's rim edge, which was the closest possible place. Hence the target was not only not quite perpendicular for all its positions to the eye surface, but also was visible usually to only the middle $135^{\circ}$ of the surface, though other parts could be exposed by centring the eye axis at a different angle. The target's movement was not 
smooth, as if often rotated and frequently jumped forward when it had lagged through slight irregularities on the dome's inner surface. This provided a rather 'jittery' motion, which was clearly much more effective than the smooth movements obtained with the previously described set-up. The instrument allowed for target movement in any direction, and such experiments showed that it made no difference in which direction the target moved with regard to the fibre's field. Hence there was no detectable directional sensitivity. The target could be moved at a variety of speeds, though not very slowly, and an automatic reversal occurred at both ends of its pathway. Usually when the movement of the target was started, e.g. midway, impulses were present until the end of the path was reached; after reversal only a few impulses ococcurred for the part already traversed, but when the target entered the unexposed region, the impulse frequency became noticeably higher (see Fig. 5, Wiersma \& Yamaguchi, 1966). On repetition almost complete habituation was then present. In some cases the discharges would show less habituation and would occur especially at the times the target stopped and reversed its motion (e.g. Fig. 9, Wiersma, 1966). However, even these discharges would disappear after a few passings. It can be concluded that any sampling station which has given a triggered response or has been exposed but prevented from contributing to the firing by the linear inhibition, causing the 'predictability' of the movement, is refractory for a considerable time.

A final device by which the 'jittery' movement fibres were investigated consisted of a box, $12 \times 12$ in., in which 196 small lamps were connected in series. A plate of white Plexiglas provided for a diffuse light emission, resulting in lighted circles separated by much darker interspaces. When a single light spot was covered a response was obtained, provided that the box was within a distance of about $30 \mathrm{~cm}$., at which the spot represented about an ommatidial angle $\left(3-5^{\circ}\right)$. If the distance was greater the response would fail, but then the simultaneous covering of two spots would trigger a similar response. It could be shown that linear movement in any direction over the surface of the box still provided for 'predictability' but to a lesser degree than with a uniform background. For instance, linear movements of large cards which covered all spots in a vertical row would now be stimulating for as much as a third or half of the total surface of the box instead of only at the edge as when a black card was moved over a white background. Single rows would trigger at each station (double rows giving the same result if the distance was too great for a single station to be effective). The fibre could be made to discharge vigorously for considerable times when the different stations were darkened one by one in a random fashion. As expected from previous findings, successive uncovering of the light spots did not result in discharges.

All these properties are also evident when a 'jittery' movement fibre reacts to a completely natural visual stimulus, as illustrated by the fact that when $\mathrm{O}_{7}$ was investigated the entrance of a small black dog walking on the floor some 2 yards away caused only a short response, unless the dog waved its tail, when every wave was accompanied by a renewed burst.

Influence from non-visual inputs. None of the factors which influence the discharges of sustaining fibres could be shown to have any clear effect on the 'jittery' movement fibres. Thus, light in other parts of the eye, or an excited state, had no effect. There was also no noticeable influence of simultaneous stimulation of the other eye, or, for 
the smaller field fibres, of movements outside that field. However, with the variability in response of these fibres to any stimulus, only rather large changes in discharge rate or discharge length would have been noticeable.

It was only late in the series of experiments that we discovered a factor which has a profound influence on the discharges of the 'jittery' movement fibres. It happened that the needle electrode, when pushed into the eyestalk, irritated the fast motor axon to the muscle which moves the eye forward for protection. As a consequence, the eye would frequently jump forward and back. With a good signal from $\mathrm{O}_{7}$ it was evident that the fibre not only showed no discharge to the apparent motion of background objects during the eye movements, but that it was also 'blind' for a 'jittery' target close to the eye. However, as soon as eye motion stopped this constantly moving target elicited a discharge, whereas before a resting eye such movement would have led to habituation. It thus appears that eye movements not only cause inhibition of the discharge, but also suppress the habituating process which normally leads to insensitivity after a short exposure.

Movements of the eyestalk, caused by pushing against it, were found to elicit the same suppressive effects. However, this may well be due to the release of motor fibre activity normally leading to the eye-withdrawal reflex, a problem which can only be resolved by further experiments. In contrast with the movement fibres the discharges of sustaining fibres were not noticeably influenced by any eye motions.

\section{Space-constant fibres}

These are a set of four fibres which share the property of having visual fields which change in size and location on the retina with the position of the animal's body in space. They differ from each other in their visual reactivity, two having, in addition to the 'space-constant' feature, all the properties of sustaining fibres, one having all those of the 'jittery' movement fibres, and the fourth being specifically sensitive to rapidly approaching objects. Of the two sustaining fibres in this class, $\mathrm{O}_{73}$ has in the normal eye position a small field which is located near the centre, collecting from an upward and backward direction. The smallness of the field makes difficult more exact determinations of its changes in size with rotations of the animal, but the results obtained indicate that these are similar to those of the larger field fibre. This fibre, $\mathrm{O}_{23}$, has in the normal eye and body position a field forming a half circle with the eye centre as midpoint and extending about halfway to the eye's periphery. By systematically changing the preparation's position in space we found that it would only respond to light in that part of the total inner circle which was above the horizontal plane. Thus, when the eye looked upward its total potential field was responsive, but when the eye was turned downward the fibre did not respond at all. Figure $\mathbf{I}_{\mathbf{I}}$ shows the changes in field size and position on the eye surface for rotations of the animal along the longitudinal and the transverse axes. In Fig. 12 part of the evidence is offered that $\mathrm{O}_{23}$ has all the other properties of a sustaining fibre. In Figs. I2 A and I $2 \mathrm{~B}$ the animal was held in the normal position and a shadow was moved at a frequency of $5 / \mathrm{sec}$. in front of, respectively, the ventral and the dorsal part of the eye. Only in the latter case was the typical reaction to this procedure present. In C and D the animal was in the upside down position, and the shadow was moved first before the dorsal part of the eye, which now was nearest to the ground. This area, which 
had given the response in $B$, now failed to do so, whereas the ventral part of the eye, the same area as stimulated in A, now showed the typical effect. (In the two positions $A$ and $C$ there may be a slight influence on the firing rhythm, due either to a very small part of the shadow still reaching the edge of the excitatory visual field or to some effect of inhibitory origin.) Both space-constant sustaining fibres also showed the normal influence of the excited state on sustaining fibres.
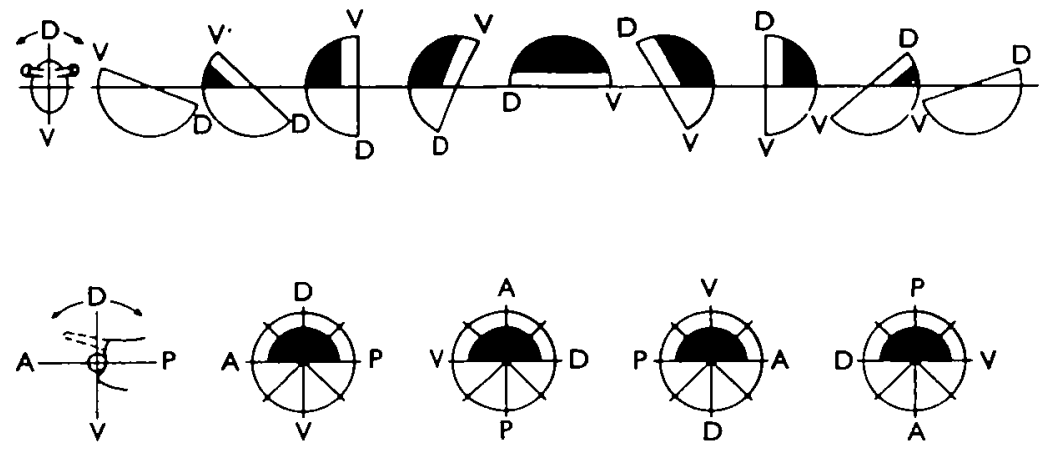

Fig. $x$. Visual field changes of space-constant sustaining fibre, $\mathrm{O}_{23}$, with rotation around the animal's longitudinal (A) and transverse (B) axis. (Adapted from Wierama, I966).

The space-constant movement fibre (O65) reacting to fast movements, especially of approaching objects, is, although large, difficult to investigate because of its 'novelty' property, which necessitates long waits between stimuli. The 'jittery' movement fibre, $\mathrm{O}_{7}$, is more favourable, and is a large and often encountered fibre. Like $\mathrm{O}_{7}$, the 'Happy Dog Fibre', of which it is a relatively close neighbour, it has in the eye-up position the whole eye as its sensory field. In a number of instances the latter two fibres were present in the same lead and it was then possible to compare their discharges to the same target movement. They usually reacted rather alike, but either could respond more vigorously than the other, and their firing patterns showed no close similarity. It therefore appears that, though they share the same collecting stations, the output of the simpler fibre is not the input for the space-constant one. This same argument is valid for a third fibre $\left(\mathrm{O}_{3} 6\right)$, a multimodal one which also has the whole eye surface as input, and reacts, in addition, to touch of hairs anywhere on the same side of the body. This fibre was also in several instances in one lead with $\mathrm{O}_{7}$ and showed a similar relationship. It thus appears that all three of these fibres share identical visual input, which is channelled to all three, and that their specific reaction patterns to the same stimulus are caused by differences in synaptic summation and perhaps in excitability of the three post-fibres. This would represent a good example of parallel computation of the same information.

In a limited number of instances we have tried to determine the source of the inhibitory effects which restrict the sensory fields of the space-constant fibres. The results were to some extent ambiguous. In some cases we obtained by removal of both statocysts (by cleaning out the cavities in which they are located) a convincing enlargement of the fibre's field to the maximum size present in eye-up position, with no further change in any position. But in a few cases there appeared to be still an influence 

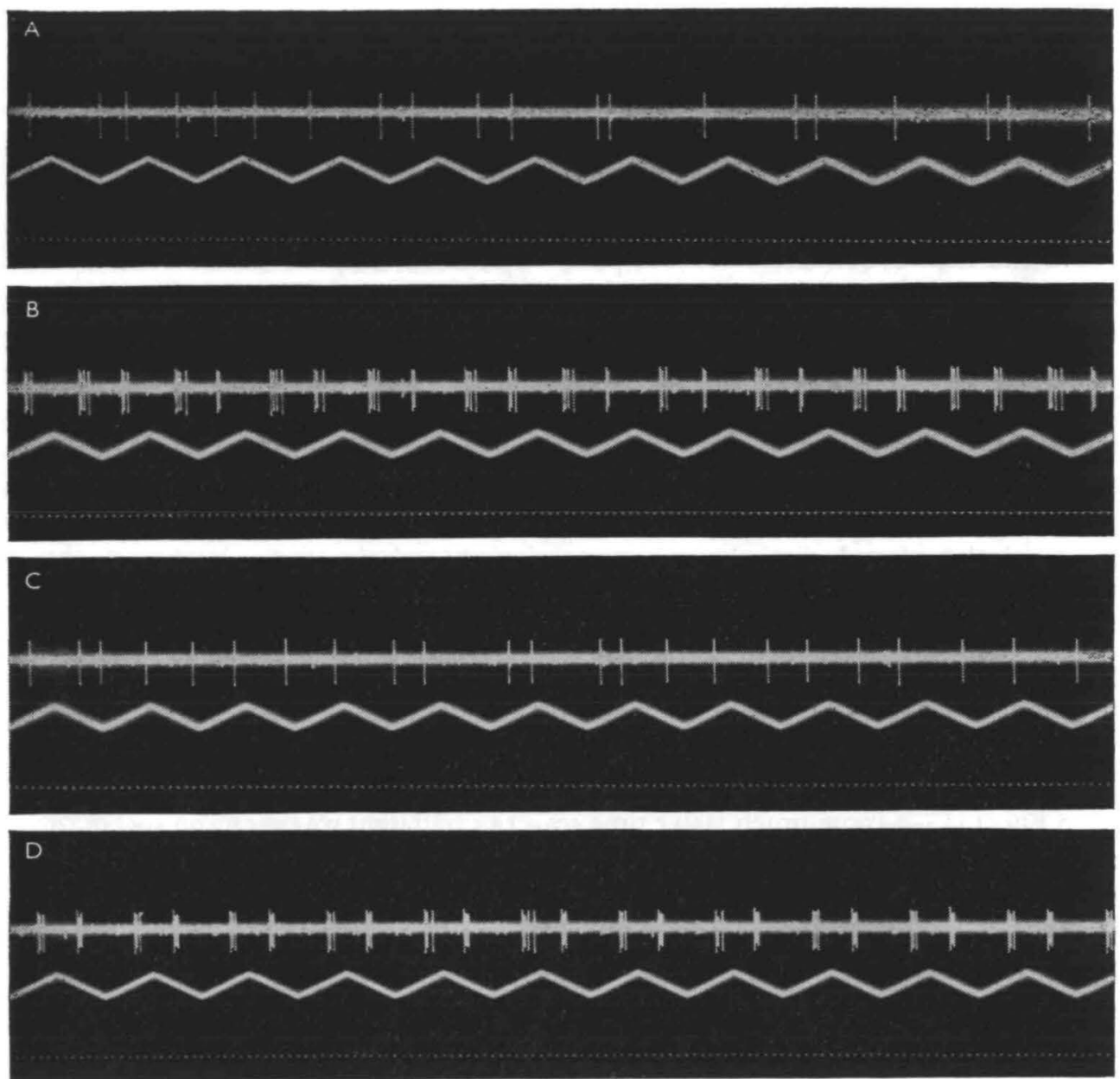

Fig. 12. Reaction of space-constant sustaining fibre $\mathrm{O}_{23}$ to a shadow ( $4 \mathrm{~mm}$.) moving through different parts of its potential excitatory field at $5 /$ sec. A. In normal position through ventral eye half; $B$, same but in dorsal eye half. $C$. In upside down position through dorsal eye half; $D$, in same through ventral eye half. Note that bursts are triggered in $\mathrm{B}$ and $\mathrm{D}$ by the two different halves. Time: $\frac{1}{8} \sec$.

of position, possibly because of incomplete statocyst removal or by activity of other input. Cutting the commissures and thus preventing input from receptors on the leg bases did not affect the phenomenon when the statocysts were present. It appears that the statocysts play by far the major role in providing the inhibitory input for the desensitization of part or all of the visual fields, but it is not excluded that other inputs, such as joint receptors of the antenna, may also have an effect.

Since extensive eye motions do not cause the space-constant movement fibres to discharge significantly, it seems that they, like the 'jittery' movement fibres, are unresponsive to the apparent motion of background objects during eye movements. But, in contrast with the findings on the other movement fibres, we have observed, for both $\mathrm{O}_{5}$ and $\mathrm{O}_{67}$, responses during eye movements to nearby moving targets. 


\section{Two optomotor fibres}

These two fibres appear to run, at the level where the needle is usually located, within the optic bundle and not in the optomotor nerve. Their code numbers are 084 and 085 . Their identification as pure motor fibres, which cannot be considered as completely definite, stems from their reactions to changes in body position, and from the fact that fibres giving the identical reactions have been found outside the optic nerve and near eye muscles in more peripheral leads. $\mathrm{O} 84$ has been also named the 'head-up' fibre, since it typically reacts with a tonic discharge, which increases in frequency the more the body is brought into a vertical position with the head pointing upward. As in other eye muscle motor fibres (e.g. eye-down fibres) which have also been extensively investigated in respect to the relationship of body position and impulse frequency, a low-frequency discharge is present in the normal position. This discharge stops in $\mathrm{O}_{4}$ when the head of the animal is inclined below the horizontal. In Fig. 13 A these positional discharges are shown on a slow time base in a preparation which was automatically turned around the transverse body axis in darkness. A rather lowfrequency discharge will be noted when the animal was near the upside down position. This discharge is due to an excited state which occurs frequently in an upside down position. But from the record it is quite clear that maximum discharge is present at the time the $90^{\circ}$ upward position is reached and that it is low or absent in all positions where the head is down. When an overhead light is on (Fig. 13 B) the positional effects are exaggerated.

In Fig. ${ }_{3} \mathrm{C}-\mathrm{F}$ (note much faster time scale) a small light was shone on specific areas of the eyes. In $\mathrm{C}$ the animal was near the horizontal position and light was shone on the ipsilateral eye in the area of the anterior rim sustaining fibre $\left(\mathrm{O}_{3} \mathrm{O}\right)$ during the marked period. This increased the discharge frequency some five times. On the other hand, when in $D$ the visual field of the sustaining fibre for the posterior rim of the eye (O14) was stimulated, an inhibition of the discharge (slightly higher because of a slight inclination of the head above horizontal) was elicited, resulting in a reduction to about half the former frequency. In $\mathrm{E}$ and $\mathrm{F}$ the effects of light on the same areas of the contralateral eye are shown to be similar. Light on any other parts of the eye had no significant influence. No influence of stimuli specific for movement fibres was found, whereas the discharge rate did respond clearly to quickly moving shadows over the fields of the excitatory sustaining fibres. We therefore believe that the light inputs bringing these effects about are by way of the interneurones $\mathrm{O}_{14}$ qnd $\mathrm{O}_{3}$, though possibly supported by the reversed discharge changes in dimming fibres with the same sensory fields.

The head-down motor fibre, 085 , is in all aspects but one the complete counter image of the head-up fibre. Its maximum tonic discharge occurs when the preparation is held head down, it is excited by light on the sensory areas of $\mathrm{O}_{14}$ and inhibited by those of $\mathrm{O}_{3}$ o. However, as for the head-up fibre, an excited state will cause the fibre to fire at a higher rate and elicit discharges when it is quiescent, a property shared also by other eye motor fibres. 


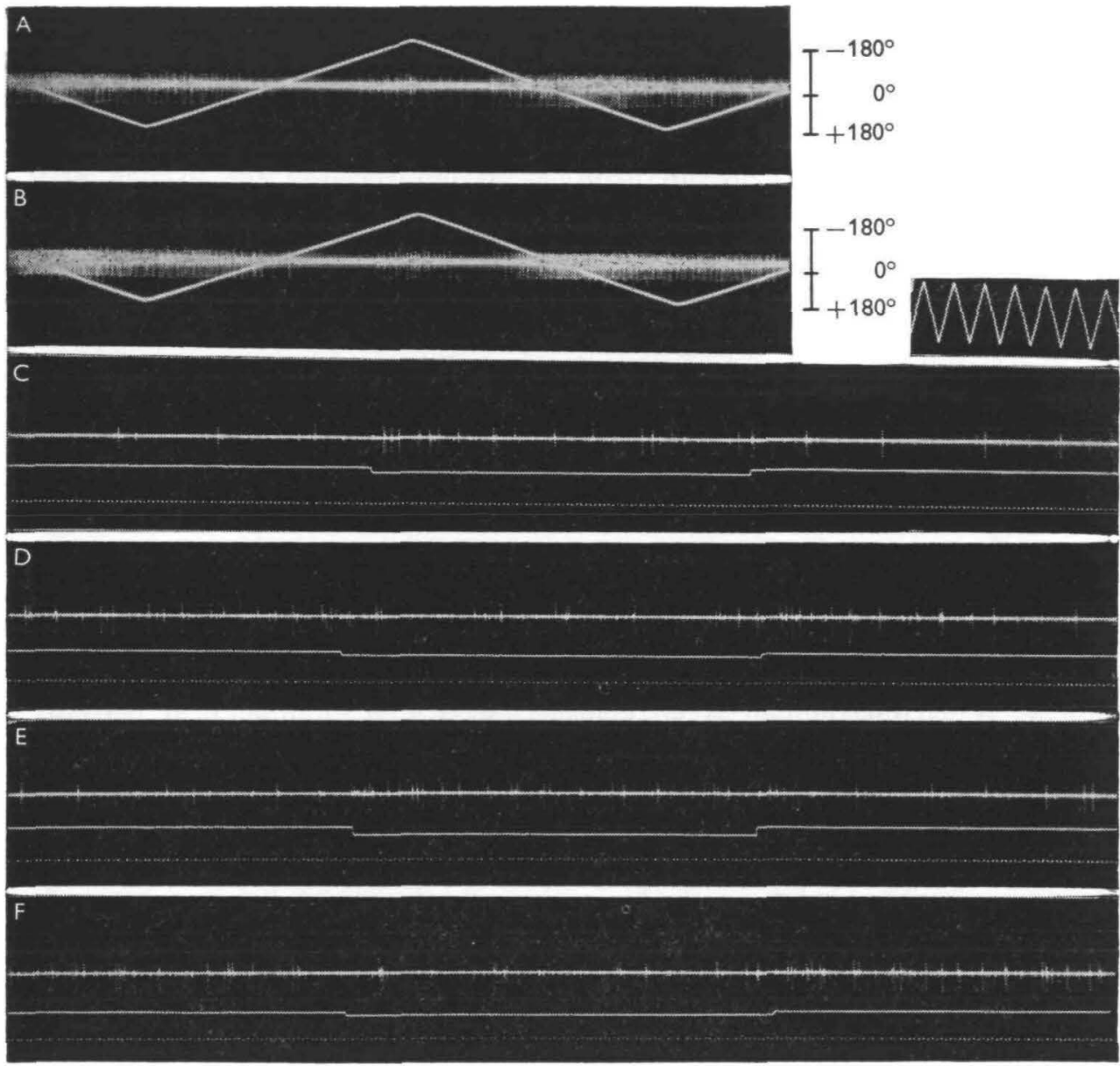

Fig. I3. Reactions of an eye muscle motor fibre, $\mathrm{O} \mathrm{84}$, to diverse stimulus situations. A. The animal was mechanically rotated in darkness around its transverse axis, starting in the horizontal position, first in head-up and then in head-down direction followed by another half cycle; $B$, same but with overhead lights on, light input at certain phases enhancing, in others diminishing, firing frequencies. $C$ and E. Animal near normal stationary position (head slightly down); light on front rim area increases frequency, both for the ipsi- (C) and contralateral $(E)$ eye. $D$ and $F$. Animal in horizontal position, In D, light on back rim area of ipsilateral eye, and in $\mathrm{F}$ on contralateral eye, inhibits the discharge. Time: $\frac{1}{6} \mathrm{sec}$. (From Wiersma, 1967).

\section{DISCUSSION}

As has been pointed out previously (e.g. Wiersma, I967), all interneurones (here used for any neurone that connects only with other neurones) found in the optic nerve of the crayfish, which convey information about visual stimuli, are of a complex nature. They invariably integrate optic stimuli from extensive receptive fields and thus from many ommatidia. Usually they experience both excitatory and inhibitory actions of the retinal input. In addition, all are influenced by sensory input from other body areas. The latter is made possible by the presence of numerous centrifugal interneurones which respond to mechanoreceptors, whose locations in the animal are 
very widespread. The influence on visual fibres by centrifugal fibres varies from modulating and inhibitory actions on the visual response to instances in which the mechanoreceptor input is the major factor, modulated by visual input. It should be appreciated that it is not possible under these circumstances to claim for any one fibre type nor for each individual member that the description of its properties is complete. For instance, it appears that many interneurones are influenced by the 'excited' state of the animal, but whether there is a linear relationship, brought about by one type of activity interneurone, or whether there are a number of interneurones involved which have various and perhaps even opposite effects is not known. In the case of the experiment pictured in Fig. 8, though there was a relationship between the firing rates of the two fibres, this changed during the experiment, indicating that either other centrifugal fibres were also involved, or even that the activity fibre pictured did not play a part.

Good examples for illustrating the difficulty in uncovering the inputs of a given interneurone are the 'jittery' movement fibres and the space-constant sustaining ones. For the first the influence of eye motions was found very late and the latter were originally considered as members of the normal sustaining type.

Two main questions arise in any study of single-unit responses of interneurones, namely, how the observed impulse trains are caused and what their functional significance is for the output in terms of reflex, behavioural, or other reactions. At present these questions must still go largely unanswered, though a number of restrictions are furnished by our experiments to the infinite variations which are theoretically possible.

The crayfish ommatidium has, as many others, seven functional retinular cells surrounding what appears to be a common rhabdome. According to Parker (1895) the retinular fibres pass through the basement membrane in groups of three of four, the fibres of any given rhabdome combining in a fixed pattern with one or two fibres from four adjoining ommatidia. He was, however, unable to determine whether or not this pattern remained constant in the first ganglion layer behind the retina, the lamina ganglionaris, where he believed that seven retinular fibres joined with a monopolar cell to form a neurommatidium. If each neurommatidium is composed of a fixed pattern of retinal fibres, all specific integrative properties of the optic interneurones must depend on the properties of the intervening networks and not on those of the retinular cells. In the crayfish, as in Pachygrapsus (Hanström, 1924), there is no evidence for interconnexions between the cells of the lamina ganglionaris, whereas in other decapods interspersed cells in this layer send nerve branches to several cells (Hanström, 1924). But in insects (e.g. Trujillo-Cenóz \& Melamed, 1966; Braitenberg, personal communication), retinular cells appear to differ in the type of connexion they make with the lamina ganglionaris cells, and, in addition, the ommatidia contributing to one secondary cell are not all immediate neighbours. This indicates that the connectivity at this level plays in insects a part in the transfer functions, and that the retinular cells are functionally specialized. Though this problem should be studied more closely in the crayfish, the known data do not indicate that specific retinular cells have specific functions.

There is evidence for some crustaceans (e.g. barnacles, Gwilliam, 1963) that the retinular cells influence the next stage not by spikes but by electrotonic potentials, which inhibit the spontaneously active second order neurones, in which inhibition of discharge thus signals illumination. In the optic nerve, the dimming fibres react 


\section{Visual integration in crayfish}

similarly and might therefore be the most directly connected with the neurommatidia, in which case they might be less influenced than the sustaining fibres by other parts of the retina.

It is impossible at present to assign the process of inhibition by the surround for the sustaining fibres to any specific element. It may come about as output from earlier dimming or sustaining elements, or both. The presence or absence of similar inhibitory influences in the dimming fibres would make one or the other hypothesis more likely. It is thus obvious that a much more accurate knowledge of the more peripheral processes is necessary to answer a number of questions, even for the 'simpler' type of optic interneurone.

The movement fibres are elements for which the preceding transformations are apparently more complex, as they clearly integrate over time. Their most remarkable property is the cessation of response when the pathway of a moving object is linear and constant in speed, independent of the orientation of this path with respect to their visual field. They are stimulated by their 'collecting' stations, which have a minimum size of one ommatidium, but may well cover four neighbouring ones or even slightly more. It is obvious that all these stations in the excitatory field feed into the fibre and that they are not summating their output when they are all triggered together, as when the total field is dimmed. It appears, therefore, that if they were not influencing each other's input by inhibition there would be a constant discharge for any object moving through the receptive field, with a short burst for fast moving objects and a prolonged one for slow moving ones. However, there must be an inhibitory network which connects all stations which are located on a great circle, and the discharge of one or two appears to inhibit those following in that direction, this influence decreasing, however, with distance. However, those stations exposed to the stimulus, but inhibited from triggering the interneurone, nevertheless must again inhibit the next ones in line and no others from triggering. The number of untriggered stations over which inhibition can jump is greater than one, since with the checkerboard arrangement the spots are also one collecting station 'distance' apart and 'habituation' still develops, though less quickly than when all stations in a line are triggered. This may be, however, almost the maximum distance, since responses re-occur at the other side of a stationary shadow only some few stations wide.

In contrast to the inhibition by the total retina for all sustaining fibres, the inhibition is here limited to boundaries of the excitatory field of the diverse individual fibres. This is shown by the fact that when a moving object enters their field the reaction is as strong when the object enters the field from a 'rim' boundary as when it has passed previously through the fields of other movement fibres. The two types of inhibitory networks cannot thus consist of the same elements.

The absence of directional sensitivity in the 'jittery' movement fibres does not need to mean that they cannot contribute to an overall, but rough, directional sense. A readout of the direction of moving objects would still be possible by the sequential stimulation of the smaller field interneurones, provided the necessary analysers are present at a higher integration level. So far there is no indication of the presence of such units.

Our knowledge about the further fate of the visual impulses in subsequent parts of the nervous system is still very fragmentary, notwithstanding several papers which have dealt with this subject (Camougis, 1964; Prosser, 1934; Wiersma \& Mill, 1965; 
Wiersma, Ripley \& Christensen, 1955). Part of the difficulty is that these investigations were made before it was known what type of information reached the brain. At the commissure level most interneurones reactive to light are bilateral and especially sensitive to movement, apparently over the whole eye surface (Wiersma \& Mill, 1965). But from our observations on the two motor fibres it is evident that much more specific relationships between optic interneurones and output exist in at least some output fibres with multiple input sources. Since it is strongly indicated that the head-up motor fibre innervates an eye muscle which turns the eye down, it follows that its light reaction to the front rim area of the retina will also turn the eye down, which would mean that the top of the eye would be turned so as to keep looking in the same direction, more specifically that the upper rim area will be kept turned toward the sun. How precise this correction could be is uncertain. There are at least four different light input areas involved in regulating the contraction of this muscle, whereas the head-down motor fibre which rotates the eye in the opposite direction is reversely influenced by the same sensory fields. Therefore, the final eye position may be much better controlled than would be expected from the considerable 'noise' present in any one intermediate channel.

In conclusion it may be pointed out that in recent experiments on the optical reactions of additional eye muscle motor fibres (Wiersma \& Oberjat, in preparation) two have been found which react specifically to moving objects in the horizontal plane of either eye. One reacts to objects moving clockwise, the other to objects moving counterclockwise, even at low speeds. None of the interneurone types described above would be capable in isolation or combination to bring about such an effect. To explain this reaction two main possibilities are then open: one, that there are present in the optic nerve numerous interneurones with pronounced directional sensitivity for back and for forward movements in the horizontal plane, each with a small sensory field; or two, that a few large field interneurones exist in the optic nerve with the necessary properties for input to the motor fibres. From preliminary exepriments the latter appears to be the case. Either way, it would be this type of movement sensitivity which might explain the remarkable observation of Horridge (1965) that a crab's eyes can follow the sun's movement.

\section{SUMMARY}

I. For the crayfish, properties of visually reacting interneurone types in the optic nerve are described on the basis of single-unit analysis.

2. Sustaining fibres show: $(a)$ 'surround' inhibition over the whole retina, including the excitatory field; $(b)$ 'on' and 'off' effects at field boundaries; $(c)$ a dark discharge in deteriorated preparations; $(d)$ an increase in adapted firing rate and response to flashes in an 'excited state' of the preparation; $(e)$ increased overall impulse frequency to fast-moving shadows at frequencies of $2-10 / \mathrm{sec}$. which elicit short bursts.

3. Dimming fibres, having mainly reversed properties, show: $(a)$ bursts followed by adaptation to a lower ferquency level of spikes on light dimming; $(b)$ total inhibition by illumination for times proportional to light intensity; $(c)$ responsiveness to quickly moving shadows.

4. 'Jittery' movement fibres lack directional sensitivity. For them: (a) total illumination and contrast have, within a wide range, no effect on discharges to moving targets; 


\section{Visual integration in crayfish}

(b) large, dark cards moved at constant speed are seen only near their visual field boundary; $(c)$ the less predictable the movement of a small dark object is, the longer its excitatory effect lasts; $(d)$ responsiveness of field parts exposed is decreased for long durations; $(e)$ no firing is caused by active or passive eye motions.

5. Space-constant fibres show changed location and size of their excitatory fields with eye position. Their potential visual fields below the horizontal plane are unresponsive, due to inhibition caused mainly by statocyst input.

6. Two eye muscle motor fibres, also under statocyst control, are influenced by light on the limited sensory fields of two pairs of identifiable sustaining fibres. The two motor fibres, which innervate antagonistic muscles, are reversely excited and inhibited by these fields.

\section{REFERENCES}

Barlow, H. B. (1953). Summation and inhibition in the frog's retina. F. Physiol., Lond. I19, $69-88$.

Barlow, H. B. \& Hill, R. M. (1963). Selective sensitivity to direction of movement in ganglion cells of the rabbit retina. Science, N.Y. 139, 412-14.

Barlow, H. B. \& Levick, W. R. ( 1965$)$. The mechanism of directionally selective units in rabbit's retina. F. Physiol., Lond. 178, 477-504.

Bush, B. M. H., Wiersma, C. A. G. \& Waterman, T. H. (1964). Efferent mechanoreceptive responses in the optic nerve of the crab Podophthalmus. F. cell. comp. Physiol. 64, 327-45.

Camougis, G. (I 964$)$. Visual responses in crayfish. II. Central transmission and integration. $\mathcal{F}$. cell comp. Physiol. 63, 339-52.

Gwlliam, G. F. (I963). The mechanism of the shadow reflex in cirripedia. I. Electrical activity in the supraesophageal ganglion and ocellar nerve. Biol. Bull. mar. biol. Lab. Woods Hole r25, $470-85$.

Hanstrôm, B. (1924). Untersuchungen über das Gehirn, insbesondere die Sehganglien der Crustaceen. Ark. Zool. 16 (10), I-1 19.

Horridge, G. A. (1965). A direct response of the crab Carcinus to the movement of the sun. Nature, Lond. 207, I 413-14.

KuFfl.kR, S. W. (1953). Discharge patterns and functional organization of mammalian retina. $\mathcal{F}$. Neurophysiol. I6, 37-68.

LetTvin, J. Y., Maturana, H. R., McColloch, W. S. \& PitTs, W. H. (i959). What the frog's eye tells the frog's brain. Proc. Instn Radio Engrs 47 I940-5 I.

PARkER, G. H. (1895). The retina and optic ganglia in decapods, especially in Astacus. Mitt. rool. Stn Neapel $12(1), 1-73$.

Prosser, C. L. (1934). Action potentials in the nervous system of the crayfish. II. Responses to illumination of the eye and caudal ganglion. 7. cell comp. Physiol. 4, 363-77.

Trujillo-Cenóz, O. \& Metamed, J. (r 966$)$. Electron microscope observations on the peripheral and intermediate retinas of dipterans. In The Functional Organization of the Compound Eye, pp. 339-61. Ed. C. G. Bernhard. Oxford: Pergamon Press.

WatzRman, T.H. \& Wiersma, C.A.G. (1963). Electrical responses in decapod crustacean visual systems. F. cell. comp. Physiol. 6r, 1-16

Watrrman, T. H., Wigresma, C. A. G. \& Bush, N. B. M. (1964). Afferent visual responses in the optic nerve of the crab, Podophthalmus. F. cell. comp. Physiol. 63, 135-55.

Wirrsisa, C. A. G. (1957). On the number of nerve cells in a crustacean central nervous system. Acta physiol. pharma, neerl. 6, 1 35-42.

Wirpsma, C. A. G. (1966). Integration in the visual pathway of Crustacea. Symp. Soc. exp. Biol. 20, $15 \mathrm{I}-77$.

WIErsmu, C. A. G. (1967). Visual central processing in crustaceans. In Invertebrate Nervous Systems, pp. 269-84. Chicago: University of Chicago Press.

Wieresma, C. A. G., Bush, B. M. H. \& Waterman, T. H. (1964). Efferent visual responses of contralateral origin in the optic nerve of the crab Podophthalmus, $\mathcal{F}$. cell. comp. Physiol. 64, 309-26.

Wiersma, C. A. G. \& MilL, P. J. (1 965). 'Descending' neuronal units in the commissure of the crayfish central nervous system; and their integration of visual, tactile and proprioceptic stimuli. F. comp. Neurol. I25, 67-94.

Wiersma, C. A. G., Ripley, S. H. \& Christensen, E. (1955). The central representation of sensory stimulation in the crayfish. F. cell. comp. Physiol. 46, 307-26.

Wiersma, C. A. G. \& Yamaguchi, T. (1966). The neuronal components of the optic nerve of the crayfish as studied by single unit analysis. $\mathcal{F}$. comp. Neurol. 128, 333-58. 